\title{
Brand Leadership in the contemporary economy
}

\author{
Andreia-Gabriela Andrei, „Al. I. Cuza” University of Iasi, Romania \\ Monica Elena Talabă, „Al. I. Cuza” University of Iasi, Romania
}

\begin{abstract}
The brand leadership as a best practice used by IBM, Sony, P\&G, GAP, Nestlé, Smirnoff, Beiersdorf (Nivea) and others was highlighted 10 years ago by professors D.A. Aaker and E. Joachimsthaler who published in 2000 the famous book Brand Leadership. In the last two years, the growing importance of brand's human interface and increased influence of information sources such as Internet and socialmedia in buying decision led to the proliferation of the brand's touch points and the emergence of social marketing. Marketing is experiencing a profound paradigm shift, because marketers can not control anymore the conversation with consumers through commissionable media. The paper outlines the importance of brand leadership in the context of changes made by social media. Overcoming the traditional vision of marketing and management and adopting brand leadership become an imperative for business success in the contemporary economy.
\end{abstract}

\section{Keywords}

brand leadership, brand management, branding, social marketing

\section{JEL Codes: M 31}

\section{Introduction}

Traditionally, the company's business goals and vision were developed in the Board, without a deep analysis of consumer. Branding, designed to support the promotion and advertising, was subordinated to the marketing department. The custody of brand used to belong to one department and the custody of staff to another one. So, no close relationship between what brand promises through advertising and how it is delivered, expressed through actions and employees behavior. This model proves to be defective today, being abandoned by successful companies. They provide increased authority to the brand manager and their business strategy is focused on brand. Brand is the concern of the top management (CEO or $\mathrm{CEO}+$ Brand Manager). Brand-related activities extend across the company, including staff direction, enabling company to deliver the brand promise through all touch points.

\section{The Brand and the Brand Strategy, pillars of the organization's plans}

In a brand-lead business the top management uses brand as a pillar of the organization. All resources are directed to deliver the promised value to consumers and shareholders, ensuring in this way, a healthy growth.. Brand strategy gives focus and direction by providing a platform for brand management that enables consistency in all actions and activities related to the brand. A company is brand-lead only when the key decisions are taken well weighing between short-term financial interests versus consistency, ability to maintain brand promise 
over the time. ${ }^{1}$ The brand strategy is the leader when it influence all day-to-day activities, from advertising to the ways in which staff answers the phone or the ways in which PR specialist manage uncontrollable events like rumors, bad online reviews and opinions, or even a dedicated website against the brand.

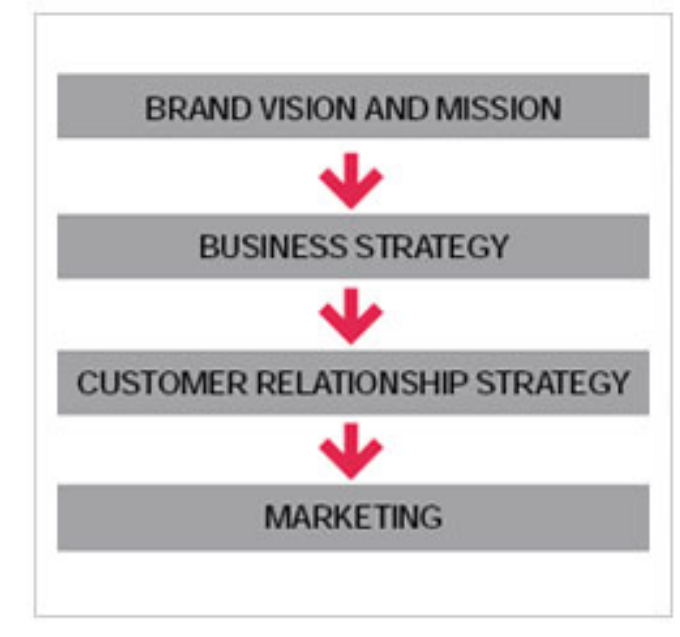

Figure.1. The link between the brand and corporate strategy

Proliferation of Internet-based communication channels and social media like blogs, podcasts, online video and social networks give voice to millions of consumer opinions. While mainstream media continues to play a vital role in disseminating information, these social channels are major levers of influence through online conversations, giving rise to a new style of marketing that is characterized by conversation and community. ${ }^{2}$ The fact is the failure of marketer's control in the conversation and increasing the importance of word of mouth, referrals and social marketing. References and opinions of the users have an increasing impact on the brand and sales, indicating as necessary the adoption of social marketing for promoting the own brand in a way that helps in promoting the consumers' and, by extension, the society's well being. Social marketing as a social leadership approach which involves the deliberate use of influence and persuasion to move the target market towards a specific course of action. Behavioral change is achieved through the creation, communication, delivery and exchange of a competitive social marketing offer that induces voluntary change in the targeted audience, and which results in benefit to the social change campaign's recipients, partners and the broader society at large. ${ }^{3}$ Such an approach is impossible without a brand-lead business.

\footnotetext{
${ }^{1}$ Aaker, D. and Joachimsthaler E. (2000), Brand Leadership: The Next Level of the Brand Revolution, The Free Press, NY

${ }^{2}$ Society for New Communications Research (2008), New Media, New Influencers and Implications for Public Relations, SNCR PRESS, USA, pp 6-7

${ }^{3}$ Dann, S. (2010), Redefining social marketing with contemporary commercial marketing definitions, Journal of Business Research, vol.63, no.2, pp 147-153
} 


\section{The customer journey outlines features for brand building}

Constructing the Consumer Journey means to project a step by step path, begining with consumer's buying decision process and continuing with consumption process. A growing importance has to be given to information gathering process, but also to the influencers' dynamics. The Consumer Journey projection forth a set of questions whose answers outline the features for a successful brand. - How complex is the process of information gathering? Where and how they are looking for? What communication channels (or media) are specific for my product category? How often customers get informed by mass-media? Are common sources of influence outside traditional media mix - consultants, agents, intermediaries,direct sales personnel, Internet, social media? What is the share of their use? What is consumer confidence which attaches to each source of information? Who are the influencers? What is their dynamic? ${ }^{4}$

\section{Positioning, planing and brand portfolio management}

Position is a guide to develop a competitive and coherent brand, offering a clear view of concrete offer - which brand should provide - and also of the human part which must be reflected in the brand's tone and feeling. A clear positioning inspires and guides the company, helping team members to speak the same language. Writing a brand plan including objective, strategy, tactics and methods of measurement is the most efficient way to specify and communicate the brand values. Branding is more than communication strategy and message. He is not only about communicating his uniqueness and his personality, but mostly about delivering brand promise and communicating it properly, not just empty words. Consumers have direct experience with brands, not with their plans. A valuable relationship with customer exists if the brand promise is delivered in an integrated way through products, additional services and message. When it is reflected in organizational culture. A common mistake is the isolated management of brands due to the lack of top coordination. What is best for a particular brand is often harmful for brand portfolio as a whole, resulting in lack of focus, poor market coverage or brands' cannibalization, inefficiency in logistics or supply, inefficient allocation of resources. Business strategy must prevail in defining brand architecture and brand alliances within the organization. Links between corporate brand and sub-brands, endorsement and mutual reinforcing can be properly done only in brand-lead company. ${ }^{5}$

\section{Brand strategy and integrated marketing communication}

Marketing and communications serve a common set of brand objectives for generating unity. They are subordinating to the brand strategy and they are coordinating to support each other. Because the audiences sometimes misinterpret messages, the management acts in direction of maximizing desired interpretations and minimizing unwanted ones. For being succesful a centralized management of branding, marketing and communication is needed. The consistency of brand and message across all audiences is necessary because all of them should be informed and even involved (employees and shareholders, customers and consumers), and they interact and are interconnected.. Advertising, packaging, price and promotions have an important common point: they are controlled by the marketing

\footnotetext{
${ }^{4}$ Adamson, A. (2008), BrandDigital: Simple Ways Top Brands Succeed in the Digital World, Palgrave Macmillan, NY

${ }^{5}$ Aaker, D. and Joachimsthaler E. (2000), Brand Leadership: The Next Level of the Brand Revolution, The Free Press, NY
} 
department. But there are factors like personnel, rumors and social media conversations that can not be kept under control. Social media gives us more opportunities to influence the opinions of hundreds or even thousands of others in discussions about products and companies. Consumer-consumer communication produces today a significant share of the amount of information available about products and companies. ${ }^{6}$ The marketing paradigm is changing. Marketers need to target social media users for inducing consumer's discussions according to the objectives of the brand's performance. References and opinions of the users have an increasing impact on the brand and sales, indicating as necessary for promoting the own brand, the adoption of social marketing as a social leadership approach which involves the deliberate use of influence and persuasion to move the target market towards a specific course of action and achieving behavioral change. ${ }^{7}$

\section{Internal brand alignment}

Brand consistency is provided only when the company personnel is the carrier and promoter of the brand promise. The brand promise is transmitted by people, from CEO to those working on the production line. Internal communication policies for encouraging the staff to live the brand are frequently used, but a lot of situations are just about talking about vision with no effect on the business running. The result is just hiding the problems of the organization and employees are disappointed by the company they are working for because of receiving a promise bigger than the offer. Practice proves that internal communication policies have a limited role in the staff training and alignment to the brand values.

\section{CEO and the brand internalization}

Enthusiastic and charismatic leaders stand behind any strong brand. They firmly believe in brand values. They are naturally followed by employees because they live the brand values, making them authentic and inspiring staff commitment to the brand and thus made brand internalization. "A further advantage of having a focus on brand management and looking more inside the organization is that it gives rise to a corporate persona with a deeply felt set of values enabling the brand to have a clear attitude." ${ }^{8}$ Staff alignment to the brand values ensures a constant quality level in delivering the brand promise by any employee (very visible especially in services).

\section{Conclusions}

Brand-lead business or Brand leadership provides a successful management model for facing the recent marketing paradigm shift. Brand becomes a top priority for the top management who integrates brand building into the overall business concept. The brand and the brand strategy are the pillars of the organization plans, directing all resources to deliver the promised value in an integrated way, through products, services, communications, personnel behavior and organizational culture. The result is a unique and valuable customer

\footnotetext{
6 Universal McCann (2008), When did we start trusting strangers? http://www.universalmccann.com/global/knowledge/view?Id=34

${ }^{7}$ Dann, S. (2010), Redefining social marketing with contemporary commercial marketing definitions, Journal of Business Research, vol.63, no.2, pp 147-153

${ }^{8}$ de Chernatony, L (2001) From Brand Vision to Brand Evaluation, Butterworth-Heinemann, Oxford
} 
relationship leading to positive word of mouth and good referrals across social media platforms enabling a competitive social marketing and a healthy brand growth.

\section{Bibliography}

1. Aaker, D. and Joachimsthaler E. (1999), The Lure of Global Branding, Harvard Business Review, vol.99, no.6, pp. 137-146

2. Aaker, D. and Joachimsthaler E. (2000), Brand Leadership: The Next Level of the Brand Revolution, The Free Press, NY

3. Aaker, D. (2004), Brand Portfolio Strategy: Creating Relevance, Differentiation, Energy, Leverageand Clarity, The Free Press, NY

4. de Chernatony, L. and Cottam, S. (2009) Interacting contributions of different departments to brand success, Journal of Business Reaserch vol.62, no.3, pp.297-304

5. de Chernatony, L (2001) From Brand Vision to Brand Evaluation,, Butterworth-Heinemann, Oxford

6. Adamson, A. (2004) To Stay On the Map, Put Your Customers There First, BrandWeek

7. Adamson, A. (2008), BrandDigital: Simple Ways Top Brands Succeed in the Digital World, Palgrave Macmillan, NY

8. Adamson, A. (2009), When Trying To Engage People On The Web, Timing Is Everything, Forbes, www.forbes.com/2009/06/22/allen-adamson-marketing-cmo-network-adamson.html

9. York, E., (2009) How to make your employees the voice of your brand online, Advertising Age

10. Dann, S. (2010), Redefining social marketing with contemporary commercial marketing definitions, Journal of Business Research, vol.63, no.2, pp 147-153

11. Society for New Communications Research (2008), New Media, New Influencers and Implications for Public Relations, SNCR PRESS, USA, pp 6-7

12. The Nielsen Company (2009) Global Faces and Networked Places

13. Universal McCann (2008), When did we start trusting strangers? www.universalmccann.com/global/knowledge/view? $\mathrm{Id}=34$ 